\title{
Do lugar do(s) mapa(s) na viagem e seu relato ou muito para além de um

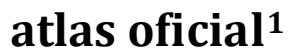

\section{Maria de Fátima Outeirinho}

Universidade do Porto - ILC

Resumo: Em estudo sobre textos de viagem, “Olhares suíços sobre Portugal: de Reynold a Loetscher”, Gonçalo Vilas-Boas observa que "Os afectos assumem também uma importância crucial na construção que os viajantes fazem daquilo que percepcionam, influenciando o modo e a atitude de observação” (2011:160); e em “Olhares sobre a Patagónia", Vilas-Boas lembra que "Cada viajante estabelece a sua cartografia pessoal, dentro de uma cartografia mais abrangente, mais global." (2014:46). Na verdade, desde sempre na relação com o espaço, com o outro, com o mundo, a representação gráfica e linguística, traduzida na conceção e desenho de um mapa, tornou-se instrumento cognitivo, ponto de partida ou de chegada, para todo aquele que pensa o seu estar no mundo, experimentando ou não, a deslocação física. Desde o mapa-múndi de Anaximandro à Carte de Tendre surgida com Clélie de Mademoiselle de Scudéry, ou mesmo aos mais contemporâneos mapas conceptuais, o processo e as dinâmicas de mapeamento dão a ver ou refiguram toda uma cartografi a pessoal e/ou coletiva de rostos e desígnios muito diversos. Assim, nesta reflexão, proponho-me apontar para processos e dinâmicas de mapeamento presentes na literatura de viagens - ou por ela convocados - e que lançam luz sobre traços, até mesmo constantes da poética do género viático.

Palavras-chave: literatura de viagens, mapa, representação diagramática
Abstract: In a study on travel writing, "Olhares suíços sobre Portugal: de Reynold a Loetscher", Gonçalo Vilas - Boas notes that "Os afectos assumem também uma importância crucial na construção que os viajantes fazem daquilo que percecionam, influenciando o modo e a atitude de observação" (2011: 160); and in "Olhares sobre a Patagónia", Vilas-Boas reminds that "Cada viajante estabelece a sua cartografia pessoal, dentro de uma 
cartografia mais abrangente, mais global." (2014: 46). In fact, always in relation to space, the other, the world, the graphic and linguistic representation, reflected in the design and in the drawing of a map, became cognitive instrument, point of departure or arrival for whosoever think his being in the world, having or not experienced a physical displacement. From Anaximander's world map to Mademoiselle de Scudéry Carte de Tendre, to even more contemporary concept maps, the process and the mapping dynamics give to see or refigure a personal and / or collective cartography of plenty different faces and purposes. Therefore in our paper, we aim to point out mapping processes and dynamics present in travel literature, or that it summons, allowing the detection of features and even the constants contained in travel writing poetic genre.

Keywords: Travel writing, map, diagrammatic representation

Em 1840, em Inglaterra, numa época em que a procura de textos de viagem se faz sentir, Frederick Marryat, ou Captain Marryat como costumava assinar os seus textos, diz pela voz da sua personagem Barnstaple, em breve texto dramático intitulado "How to write a book of travels":

Barnstaple. Why, Ansard, my dear fellow, with a book of roads and a gazetteer, I would write a more amusing book of travels than one half which are now foisted on the public. All you have to do is to fill up the chinks. (Marryat 1840: 287)

Num quadro mais geral de vulgarização, mas também de menorização criativa da narrativa viática, esta era uma das muitas dicas dadas ao seu amigo para que pudesse escrever um livro de viagens, sem sair da sua poltrona. No século XXI, em $A$ arte da viagem, Paul Theroux, aclamado autor de textos de viagens, lembra algumas regras para viajar, da escritora-viajante Dervla Murphy. Uma delas diz-nos: "INVISTA NOS MELHORES MAPAS QUE HOUVER/ E, faça o que fizer, não se esqueça da bússola." (Theroux 2012: 70) E em "O essencial da viagem", último capítulo da obra, dos 10 itens indicados, o quarto é, precisamente, "Levar um mapa” (idem: 358).

Em Viagens e outras viagens, recolha de textos que não foram escritos para integrar a 
literatura de viagens (Tabucchi 2013: 9) e que oferece itinerários num espaço físico e num espaço de leitura, Antonio Tabucchi, em excerto do escrito “Atlas", recorda, numa apreciação lucidamente analítica, um dos seus livros mágicos do tempo da adolescência, o atlas De Agostini, e lembra ainda o processo de construção cultural de que o mapa é também o resultado:

Na primeira ilustração do atlas, o globo dividido em dois como uma laranja, e depois as ilustrações sucessivas dos vários continentes. Começava-se pela Europa uma vez que, segundo os europeus, o mundo começa na Europa. De resto aquele atlas não podia ter acolhido a antropologia cultural, quer dizer, o relativo. 0 que mais me fascinava era que na página da direita estava representado um continente e na da esquerda havia uma espécie de fotografias "representativas" do continente em questão. Recordo-me de algumas da Europa: o coliseu, a Torre Eiffel, a Sereiazinha de Copenhaga, a ponte de Londres. De África apareciam, entre outras, as pirâmides, o Kilimanjaro, uma mesquita de Marrocos, uma cidade de argila do Mali. Da Ásia, o porto de Singapura, um pagode de Tóquio e uma vista de Samarcanda. Para a Oceânia lembro-me do porto de Sydney e do rosto de um homem com um osso enfiado no nariz. Aquele era o mundo. E aquela foi a minha primeira ideia de Terra. Para mim era imutável e segura, porque de um lado estava a representação abstracta da sua forma e do outro as imagens fotográficas, o "conteúdo". ${ }^{2}$ (idem: 23-24)

Servem estas referências o propósito de apontar para o lugar do mapa ou, para ser mais precisa, do lugar do(s) mapa(s) já que a sua pluralidade conceptual e funcional está aqui presente. Mas o que podemos então definir como sendo mapa? Numa aceção dicionarística, três caminhos de resposta podem ser encontrados: delineação convencional de uma qualquer extensão da superfície da Terra, relação (lista), quadro sinótico $^{3}$. Contudo, muito para além destas possibilidades de definição, o mapa precisa ou pode também ser entendido enquanto modo de ver o mundo, revelando um ponto de vista, um conjunto de escolhas, uma memória sobre o mundo, aproximações afinal a um conhecimento do mundo, dando a ver, por exemplo, um mapeamento singular que resulta de uma deslocação no espaço, mas que se autonomiza criativamente dele, como de resto Atlas $^{4}$ de Jorge Luis Borges testemunha.

Assim e desde sempre na relação com o espaço, com o outro, a representação gráfica 
e linguística, traduzida na conceção e desenho de um mapa torna-se instrumento cognitivo, ponto de partida ou de chegada, para todo aquele que pensa o seu estar no mundo, experimentando ou não, a deslocação física.

Com efeito, desde o mapa-múndi de Anaximandro, a trabalhar um conhecimento à época de um espaço em torno do Mar Egeu, da Carte de Tendre surgida com Clélie de Madeleine de Scudéry, a dar conta de um país da sensibilidade, dos afetos e das emoções, situado - et pour cause - na costa do Mar Perigoso, até mesmo aos mais contemporâneos mapas conceptuais, o processo e as dinâmicas de mapeamento dão a ver ou refiguram toda uma cartografia pessoal e/ou coletiva de rostos e desígnios muito diversos.

Se no Dicionário de Lugares Imaginários Alberto Manguel e Gianni Guadalupi compendiam todo um conjunto considerável de construções de mundos que atravessam a literatura no fio do tempo, formas afinal de alargamento do mundo físico e minorações da terra incognita e que, segundo Manguel revelam um "função humana vital: a de dar vida ao que não pode reclamar presença no mundo do volume e do peso" (Manguel 2013: XII), para além desta cartografia do lugar imaginário, outra possibilidade de construção mental tem lugar, assente num imaginário do lugar deixado em herança, base sobre a qual se erguem novas possibilidades de reconfiguração e que sobretudo estão presentes na literatura de viagens. Porém, casos há, como na obra Viagem a Tralala de Wladimir Kaminer (2012) em que lugar imaginário e imaginário do lugar se entrecruzam fazendo emergir novas dinâmicas e novos desafios para a entidade leitora, no que respeita por exemplo à presença de processos paródicos nos textos de viagem e, na questão em apreço, em torno da relação com e da construção do lugar (Outeirinho 2014).

Passando do lugar imaginário ao imaginário do lugar, recordem-se os estudos de 2011 e 2014 de Gonçalo Vilas-Boas sobre textos de viagem, que de algum modo atentam na construção de mapas singulares. Em "Olhares suíços sobre Portugal: de Reynold a Loetscher", observa-se que "Os afectos assumem também uma importância crucial na construção que os viajantes fazem daquilo que percepcionam, influenciando o modo e a atitude de observação" (2011:160); em “Olhares sobre a Patagónia”, lembra-se que "Cada 
viajante estabelece a sua cartografia pessoal, dentro de uma cartografia mais abrangente, mais global." (2014:46)

Não querendo parecer ter sido atingida pela moda do mapping denunciada por Michel Collot (2014: 59), importa-me no entanto apontar para processos e dinâmicas de mapeamento presentes na literatura de viagens - ou que ela convoca - e que lançam luz sobre traços, até mesmo constantes da poética do género viático que lida com mapas de estradas, mapas físicos, mapas políticos de que tantas edições se fazem acompanhar - e mencione-se tão somente o paratexto cartográfico da coleção de literatura de viagens publicada pela Tinta da China -, mas ainda a possibilidade de mapear no interior do próprio relato uma rede conceptual que aponta para uma construção cultural em torno do espaço de que se faz a experiência.

Como lembra Collot em capítulo sobre abordagens geográficas da literatura, em Pour une géographie littéraire, o mapa, enquanto representação gráfica, na sua relação com a literatura pode servir várias funções: visualizar uma geografia da literatura no que toca aos lugares de produção ou de receção, ou aos referentes geográficos de um texto literário (Collot 2014: 83)5, mas também, e integrado na obra literária, "[la carte] peut attester l'ancrage de la fiction dans une géographie réelle ou vraisemblable et faire de celle-ci un tremplin pour l'imagination." (idem: 84) Contudo, este tipo de mapa apresenta limites em termos de representação totalizadora dessa mesma geografia literária. Na verdade, e seguindo ainda Collot,

Elle objective et rationalise un espace irréductiblement subjectif, qu'elle désocialise en le vidant de ceux qui l'habitent et le fréquentent. Elle le réduit au visible, alors qu'il est aussi perçu par d'autres sens, ressenti et imaginé. [...] En somme, elle prive l'espace d'horizon. (ibidem)

No quadro de uma geocrítica de Lisboa, Alain Montandon recorda a existência "d'un imaginaire préconstruit”, pois “des bagages, il y en quand même” (Montandon 2006 :89). Ora, por maioria de razão, quando se trata de considerar os textos de viagem, não há como ignorar todo um imaginário do lugar que precede a experiência que se faz do real e sobre ela age, e de que o relato é a representação. Com efeito, a literatura de viagem constrói-se 
sobre a importância do referente espacial, sobre um espaço percorrido, no confronto com um imaginário herdado, posto à prova na vivência do eu viajante que por sua vez o trabalha, revisitando-o, para o reproduzir ou redescrever.

Como em ocasião anterior tive oportunidade de considerar, 6 a abordagem dos textos de viagem terá muito a ganhar com a mutação epistemológica que o spatial turn vem introduzir, na medida em que os contributos conceptuais e críticos da geocrítica assentam precisamente na complexidade das relações diferenciais entre espaços literários e espaços reais. Bertrand Westphal, nas suas reflexões em torno da geocrítica, refere que "L'espace est un feuilleté qui réactive des couches de passé à mesure qu'il se dévoile." (2006:9) e daí a importância em atentar na existência de estratos que os textos podem integrar. Westphal não deixa de considerar a narrativa de viagens, sublinhando que neste tipo de textualidade

Malgré la relativisation grandissante du concept d'exotisme, le récit de voyage s'est perpétué. Peutêtre même a-t-il continué à s'affirmer. Le voyageur ne se cantonne plus dans le seul spectacle sensible du monde. Il rend compte de la qualité abstraite des espaces qu'il parcourt ; il instaure une véritable réflexion sur la nature des espaces humains. (Westphal 2007 : 46)

Neste sentido, a experiência da espacialidade que se faz pela evocação-invocação de leituras múltiplas, de textos outros, de camadas de múltiplas leituras e que parece constituir uma das constantes da poética do género, resultam num funcionamento em rede do texto de viagem, num processo de arborescência que um mapa genético e/ou conceptual poderia representar. ${ }^{7}$

Se no contexto da geocrítica, como refere Westphal, "Il s'agira de sonder les espaces humains que les arts mimétiques agencent par et dans le texte, par et dans l'image, ainsi que les interactions culturelles qui se nouent sur leur patronage." (idem: 17), através de uma abordagem que explora e valoriza dinâmicas relativas à estratigrafia, polisensorialidade, multifocalização ou intertextualidade (Westphal 2006; Westphal, 2007), no que à narrativa de viagens diz respeito tal procedimento ganha acuidade, permitindo desenvolver um trabalho de identificação de camadas de memória, em torno de camadas 
textuais, revelando afinal que as narrativas de viagem também elas mostram e demonstram que

La réalité de l'espace géographique n'est donc pas réductible aux seuls éléments dont nous pouvons prendre objectivement conscience: il est constitué également, et surtout, par ces différentes représentations, ces différents filtres imaginaires qui sont constitutifs de notre rapport au monde. (Dupuy \& Puyo 2015 : 22-23)

Assim, o texto de viagem organiza-se não apenas em relação a um referente espacial situado geograficamente num mapa físico, mas também em relação a um referente literário, pictórico ou fílmico que acolhe e trabalha um imaginário sobre uma espacialidade construída culturalmente, ancorando-se então numa memória coletiva partilhada (Ver Figura 1).

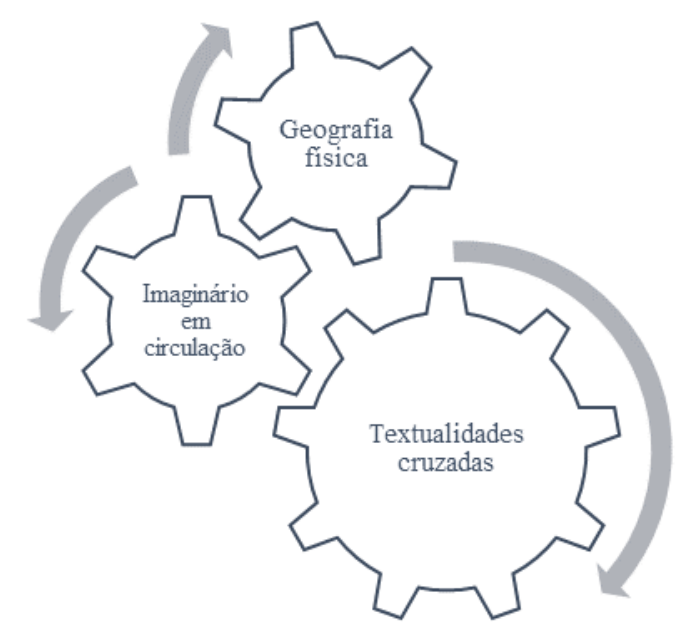

Figura 1: Representação do processo de organização presente no texto de viagens.

Deste modo, a constituição do lugar ergue-se a partir desses imaginários geográficos $^{8}$ a que as narrativas de viagens dão voz, mapeando ainda por palavras uma geografia mental e dos afetos, difícil de materializar graficamente. Ora, o próprio caráter reticular do texto de viagem poderá ajudar a ultrapassar a aporia de uma cartografia física, sendo talvez então pertinente atentar numa redescoberta do texto no sentido de gerar o seu mapeamento conceptual. Neste contexto, a elaboração de mapas conceptuais, assentes em 
representações diagramáticas, potenciaria uma visualização de todo um processamento cognitivo da relação com o mundo e com a informação deixada em herança e consequente sistematização, uma identificação relacional de imaginários presentes em diversas literaturas nacionais e a clarificação de fenómenos transnacionais; um mapeamento afinal de correlações entre vários sistemas literários, o desenho de uma estrutura a permitir identificar a circulação de representações culturais no fio do tempo e sua eventual reconfiguração, no reconhecimento das camadas do palimpsesto que a literatura de viagens também é.

Etapa prévia a esta possível cartografia do imaginário do lugar, não pode porém deixar de estar uma cuidadosa delimitação de corpora, com base na eleição de traços partilhados por um conjunto de textos, com vista à coesão e coerência de um corpo ligado por um sistema de vasos comunicantes.

Como exemplo micro e meramente indicial da potencialidade dos textos de viagem no que toca a este tipo de abordagem, consideremos o exemplo de uma só obra: $O$ murmúrio do mundo. A Índia revisitada de Almeida Faria. ${ }^{9}$ Livro surgido após uma viagem acontecida em 2006, sob o patrocínio do Centro Nacional de Cultura, explorando o eixo "Os portugueses ao encontro da sua história”, ela dá conta de um percurso nalguma Índia contemporânea, mas a convocar igualmente uma Índia da memória dos portugueses e erige-se sobre uma revisitação de uma tradição literária portuguesa, revelando de facto uma mobilidade num espaço físico, no imaginário construído em torno desse espaço, no espaço literário e artístico. Assente em processos dialógicos, a construção textual deste texto de viagens de Almeida Faria aciona diferentes movimentos: do hoje para ontem ou do ontem para o hoje, do texto do narrador-viajante para o texto do(s) outro(s) - ou no seu movimento inverso - quase sempre não identificado ${ }^{10}$, o itálico surgindo como modo de apontar para uma autoria outra, resultando afinal num diálogo a várias vozes, numa escrita a várias mãos, numa aproximação de experiências ligadas a temporalidades distintas. Com efeito, a leitura de $O$ murmúrio do mundo resulta da experiência que se faz de um universo polifónico que a obra encerra, pondo em relação, entrelaçando e presentificando vozes 
várias originalmente inscritas, muitas delas, num tempo passado, pertencendo a mundos linguísticos e culturais diversos, cultivando textualidades várias. ${ }^{11}$

Mapa físico, mapa político, mapa conceptual, mapas da memória... Múltiplas são as possibilidades de mapeamento que $O$ murmúrio do mundo autoriza, podendo resultar numa identificação sistematizada e relacional de dinâmicas de releitura, reescrita, reconfigurações de mundos.

Lembro apenas o início da narrativa marcado já por uma autoria plural e a cruzar imaginário coletivo e imaginário pessoal:

Despachadas as cousas todas, o Governador se embarcou e se fez à vela meado março, indo ele embarcado na nau de São Thomé. Em a qual frota, além de gente ordenada para a navegação das naus, iriam até mil e quinhentos homens de armas, todos gente limpa, em que entravam muitos fidalgos $e$ moradores da casa de el-rei, os quais iam ordenados para ficar na Índia, e por regimento que el-rei então fez eram obrigados a servir lá três anos contínuos.

Despachada a bagagem dita de porão, embarcámos aos trinta dias de novembro num avião sem nome de santo mas dotado do dom de trespassar os céus a altas velocidades. Além da tripulação e dos outros passageiros, éramos cerca de três dezenas de gente limpa em que entravam alguns antigos e atuais moradores da casa da governação do Estado, e não nos esperavam meses e meses sem fim no mar até à Índia, nem lá ficaríamos três anos contínuos. (Faria 2012: 19)

Em jeito de síntese provisória, importa assim considerar que, tal como na sua relação com a geografia se desenvolveu toda uma cartografia temática, valerá certamente a pena equacionar, no plano de estudo da literatura de viagens, uma representação cartográfica conceptual com vista ao estudo de espaços discursivos fecundos para o estudo da espacialidade e da construção do lugar. Apresentando muito embora um caráter subsidiário, o processo de mapeamento para o qual aqui se aponta revela um valor heurístico a ter em conta, enquanto contributo que é para a leitura de um espaço imaginado, podendo ainda levar à identificação do que não vem no mapa e com isso gerar novos questionamentos críticos em torno dos textos de viagem, permitindo identificar traços construtivos caracterizadores dessas narrativas. Parafraseando Almeida Faria, 
atrevo-me neste caso a pensar que tais processos de mapeamento mesmo sendo talvez aproximações precárias, podem no entanto tornar-nos mais atentos à infindável memória do mundo, mais capazes de escutar o incansável murmúrio do mundo,12 ao ousarmos a sua fixação.

\section{Bibliografia}

Collot, Michel (2014), Pour une géographie littéraire, Paris, Éditions Corti.

Borges, Jorge Luis (1998), Atlas, in Obras Completas, 1975-1985, vol. III, Círculo de Leitores. Dupuy, Lionel \& Puyo, Jean-Yves (2015), “Introduction générale”, in Dupuy, Lionel \& Puyo, Jean-Yves (dir.), L'imaginaire géographique. Entre géographie, langue et littérature, Presse de l'Université de Pau et des pays de l'Adour, collection "Spatialités", pp. 21-28.

Faria, Almeida (2012), o murmúrio do mundo. A Índia revisitada, Lisboa, Tinta da China Edições.

Kaminer, Wladimir (2012), Viagem a Tralala, Lisboa, Tinta da China Edições.

Manguel, Alberto \& Gauadalupi, Gianni (2013), "Prefácio à edição portuguesa”, Dicionário de lugares imaginários, Lisboa, Tinta da China Edições, pp. XI-XXXI.

"Mapa", in Dicionário Priberam da Língua Portuguesa [em linha], 20082013, http://www.priberam.pt/dlpo/mapa [consultado em 01-12-2015]. 
Marryat, Captain (1840), "How to write a book of travels", Olla podrida, London, George Routledge and Sons, pp. 286-297, https://archive.org/stream/ Captain_Marryat_Olla_Podrida\#page/n287/mode/2up_[consultado em 01-12-2015].

Montandon, Alain (2006), "Traversée de Lisbonne”, in Montandon, Alain (dir.), Lisbonne. Géocritique d'une ville, Clermont-Ferrand, Presses Universitaires Blaise-Pascal, pp. 87-95.

Moretti, Franco (1998), Atlas of the European novel. 1800-1900, London-New York, Verso.

Moretti, Franco (2003), "Maps, graphs and trees. Abstract models for literary history 1", New Left Review, 24 (nov.- dec.), http://www.mat.ucsb.edu/ g.legrady/academic/ courses/09w259/Moretti_graphs.pdf, pp. 67-93 [consultado em 01-12-2015].

Outeirinho, Maria de Fátima (2014), “Des topoi de la littérature de voyage à son approche parodique", Cadernos de Literatura Comparada, nํ 30 (junho), pp. 121-132.

Tabucchi, Antonio (2013)., Viagens e outras viagens, Alfragide, D. Quixote.

Vilas-Boas, Gonçalo (2011), "Olhares suíços sobre Portugal: de Reynold a Loetscher", Cadernos de literatura comparada, Porto, FLUP /Instituto de Literatura Comparada Margarida Losa, no 24/25 (dezembro), pp. 137-165

Vilas-Boas, Gonçalo (2014), "Olhares sobre a Patagónia”, Cadernos de literatura comparada, Porto, FLUP /Instituto de Literatura Comparada Margarida Losa, no 30 (junho), pp. 45-63.

Westphal, Bertrand (2006), " Pourquoi une géocritique de Lisbonne ?”, in Montandon, Alain (dir.), Lisbonne. Géocritique d'une ville, Clermont-Ferrand, Presses Universitaires BlaisePascal, pp. 7-20.

Westphal, Bertrand (2007), La Géocritique. Réel, fiction, espace, Paris, Editions de Minuit. 
Maria de Fátima Outeirinho é Professora Auxiliar da Faculdade de Letras da Universidade do Porto, onde lecciona nas áreas dos Estudos Franceses e da Literatura Comparada, tendose doutorado precisamente nesta última área de conhecimento com uma tese sobre $O$ Folhetim em Portugal no Século XIX: uma nova janela no mundo das letras (2003). Integra o grupo "Inter/transculturalidades" no quadro do projecto Literatura e fronteiras do conhecimento: políticas de inclusão, do Instituto de Literatura Comparada Margarida Losa, no âmbito do qual desenvolve investigação, nomeadamente, no domínio da Literatura de Viagens, campo também de docência. Tem como principais domínios de investigação a Literatura Comparada, Literatura e Cultura Francesas (Séculos XVIII e XIX), Relações Literárias e Culturais Portugal-França, Estudos sobre as Mulheres, Literatura de Viagens. É autora e organizadora de diversos estudos críticos nestes domínios.

\section{NOTAS}

${ }^{1}$ Este artigo foi desenvolvido no âmbito do Programa Estratégico integrado UID/ELT/00500/2013 | POCI-010145-FEDER-007339

20 negrito é da nossa responsabilidade.

${ }^{3} \mathrm{Cf} . \underline{\mathrm{http}: / / w w w . p r i b e r a m} . \mathrm{pt} / \mathrm{dlpo} / \mathrm{mapa}$

${ }^{4}$ Esta obra, na sua primeira edição, integrava ainda fotografias de Maria Kodama.

${ }^{5}$ Cf. Franco Moretti, Atlas of the European Novel. 1800-1900 (1998) ou o estudo iniciado com "Maps, graphs and trees. Abstract models for literary history 1" (Moretti 2003).

6 Cf. Intervenção no encontro científico Géographie, Langue et Textes Littéraires: écrire le lieu, fictionnaliser l'espace, realizado na Faculdade de Letras do Porto, em 23 e 24 de abril de 2015.

${ }^{7}$ Os estudos de Franco Moretti que incorporam representações diagramáticas, não tendo por objeto a literatura de viagem, deixam no entanto antever possibilidades de aplicação produtiva também neste campo. 
Neste artigo, porém, limitamo-nos a uma dimensão exploratória que poderá vir a ser desenvolvida em estudos posteriores.

${ }^{8}$ Seguimos a definição adotada por Lionel Dupuy et Jean-Yves Puyo: "[...] l'ensemble de représentations, images, symboles ou mythes porteurs de sens par lesquels une société (ou un sujet) se projette dans l'espace" (Dupuy \& Puyo $2015: 21$ )

${ }^{9}$ Não é nosso propósito neste estudo explorar esta obra de Almeida Faria, mas tão só apontar para o caráter promissor de uma abordagem do texto de viagem no que toca à identificação de processos de mapeamento do mundo assente numa dinâmica intertextual, através de um instrumento de análise que passa pela exploração de representações diagramáticas.

10 Muito embora num apartado final se ofereça ao leitor uma listagem de autores com a seguinte nota prévia: “Frases em itálico sem indicação da sua origem são dos autores seguintes [...]" (Faria 2012: 145).

${ }^{11}$ São muitas as mãos a escreverem o texto de Almeida Faria: Camões, Gil Vicente, Diogo do Couto, Garcia da Orta, Antero de Quental, Oliveira Martins, Nietzsche, Álvaro de Campos, Jaime Cortesão, Cecília Meireles, Joseph Conrad, Eduardo Lourenço, Luís Quintais, J. M. Co etzee.... e tantos outros.

12 V. "E tornei-me mais atento à infindável memória do mundo, mais capaz de escutar o incansável murmúrio do mundo." (Faria 2012: 143). 